\title{
Regional-scale landslide and erosion monitoring utilizing airborne LiDAR change detection analysis
}

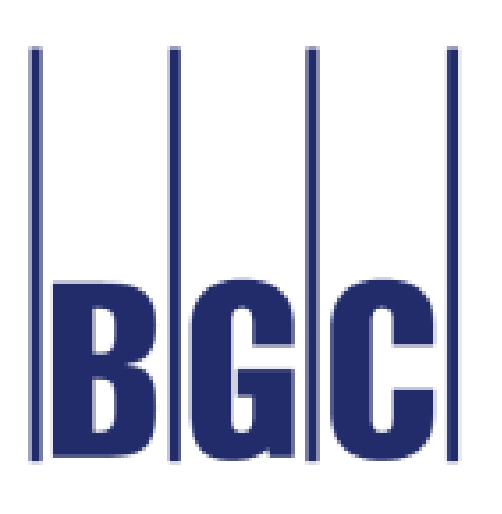

October 23, 2017

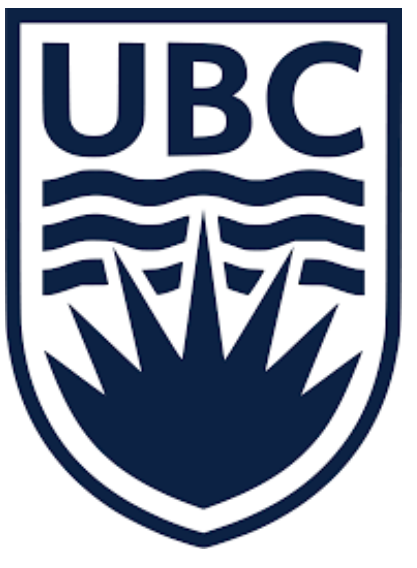




\section{Motivation}

- Variety of projects exposed to landslide and erosion risks over large spatial extents

- Transportation corridors

- Electrical infrastructure

o Pipelines

- Areas of instability and erosion can be located and delineated using field mapping

- Very rich source of information

o Labour intensive to collect

- Remote sensing techniques can be used for rapid detection of areas requiring greater scrutiny

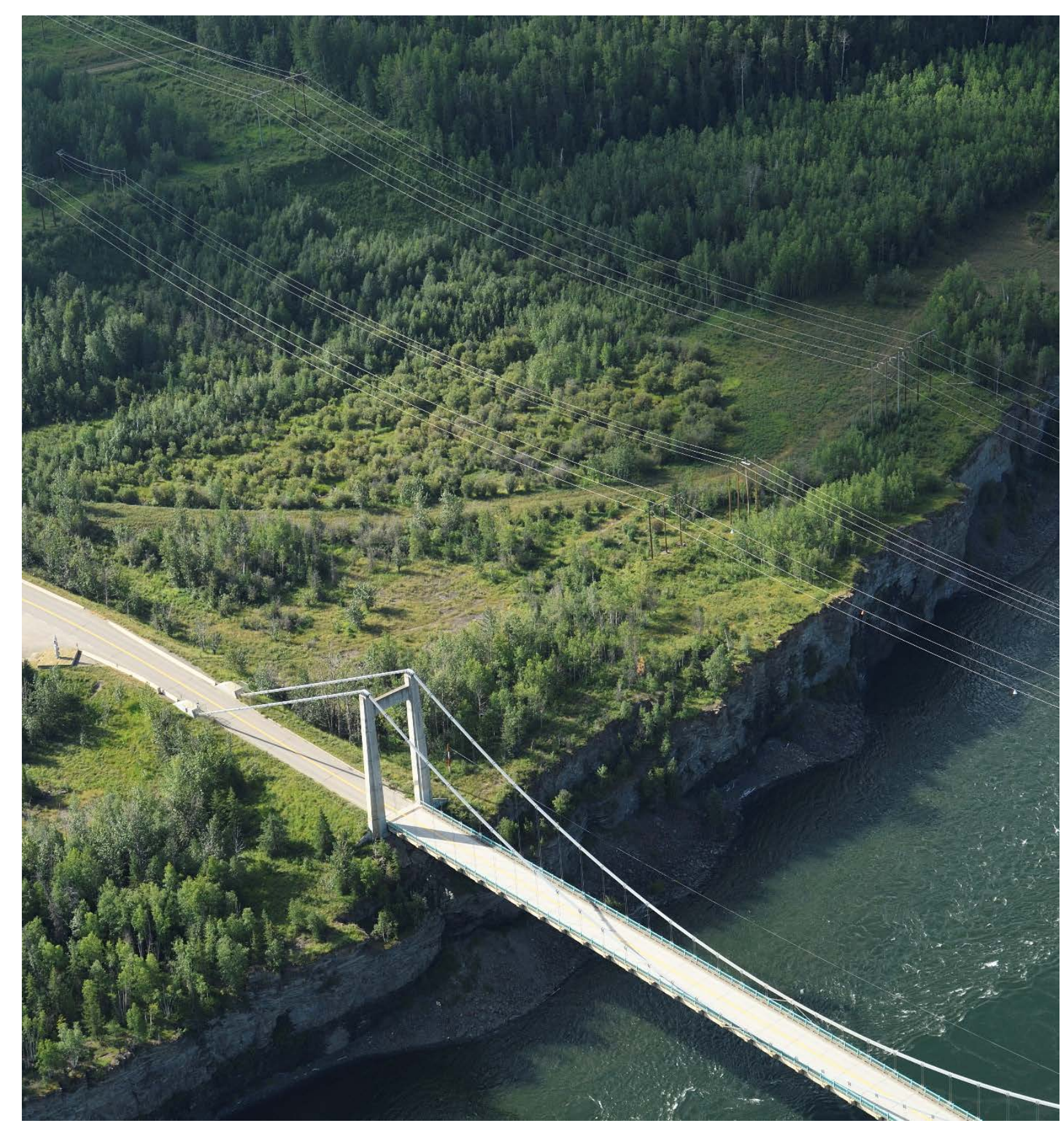

Photo: M. Porter 


\section{ALS for Geohazards Monitoring}

- Airborne LiDAR Scanning (ALS) has become common for many engineering and geology applications

- Bare earth data gives an improved perspective on geohazards for vegetated slopes

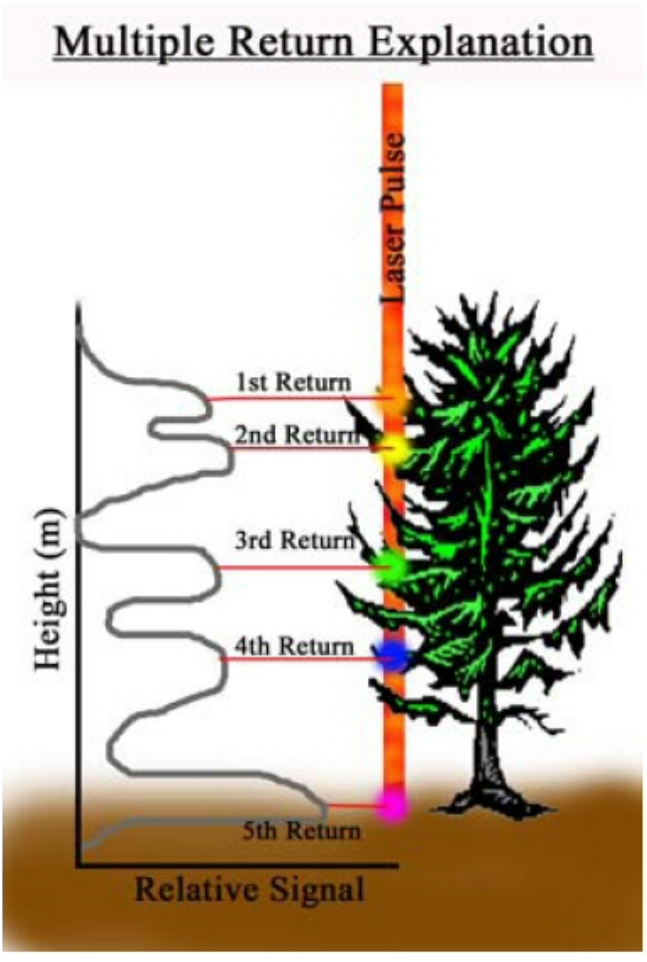

Fancher 2012
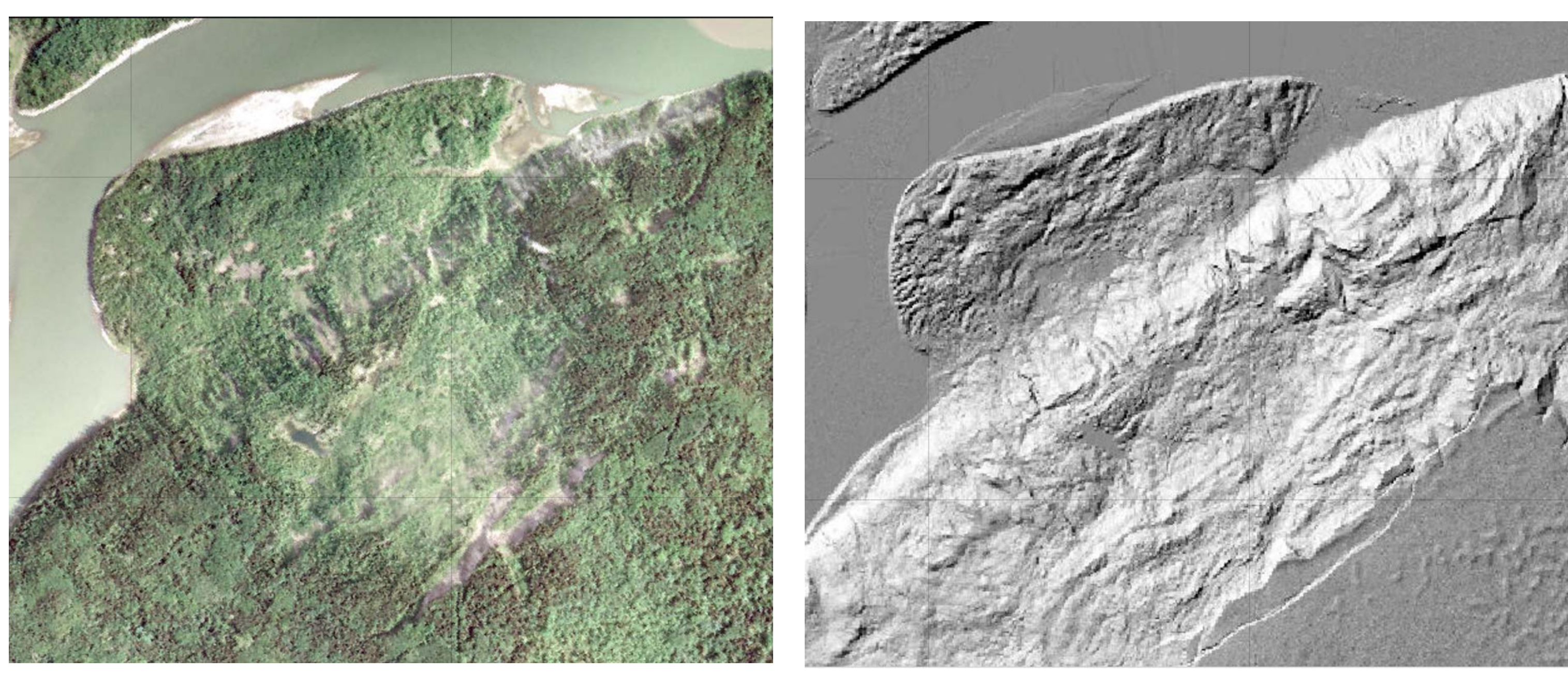


\section{Change Detection Analysis}

- Requires at least two data collections separated in time

- Three main steps

- Alignment of the active and reference data sets for areas not suspected of changing - requires an assumption of what is and is not moving

- Calculate a limit of detection for non-moving areas - there will be variation in the point clouds in the non-moving areas, the limit of detection is between $2.5 \%$ and $97.5 \%$ of the cumulative distribution of errors.

- Calculate the 3D shortest distance change between the points of the complete active dataset to the mesh of the reference dataset

- Typically done for local areas of interest

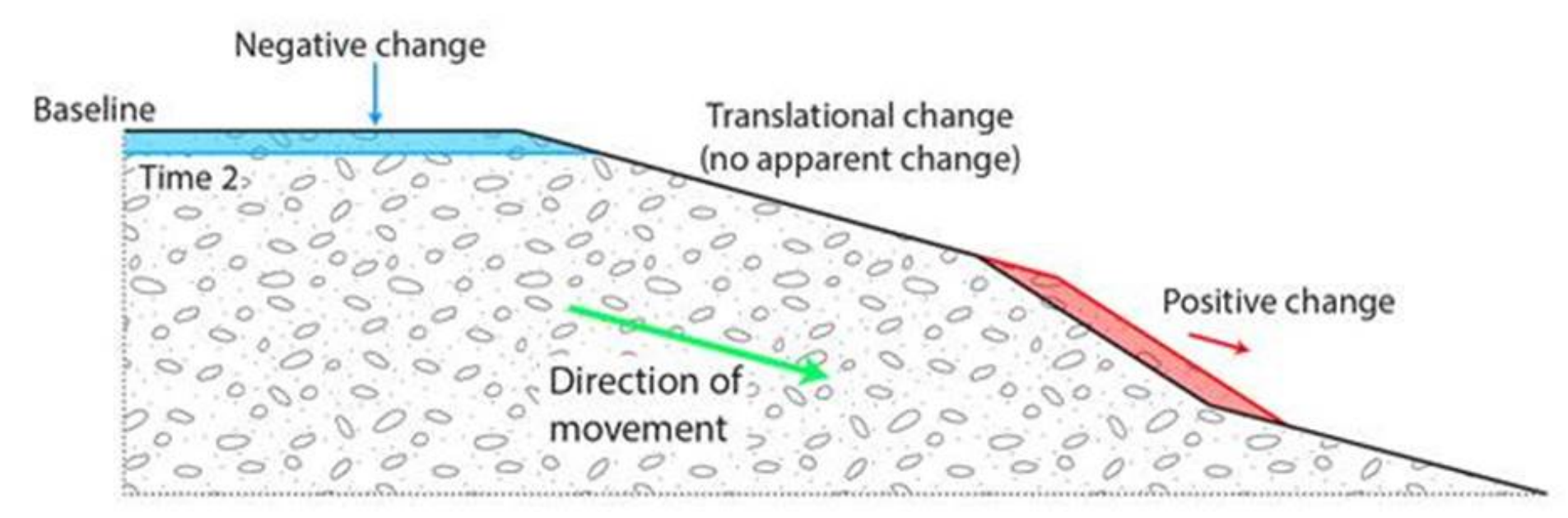

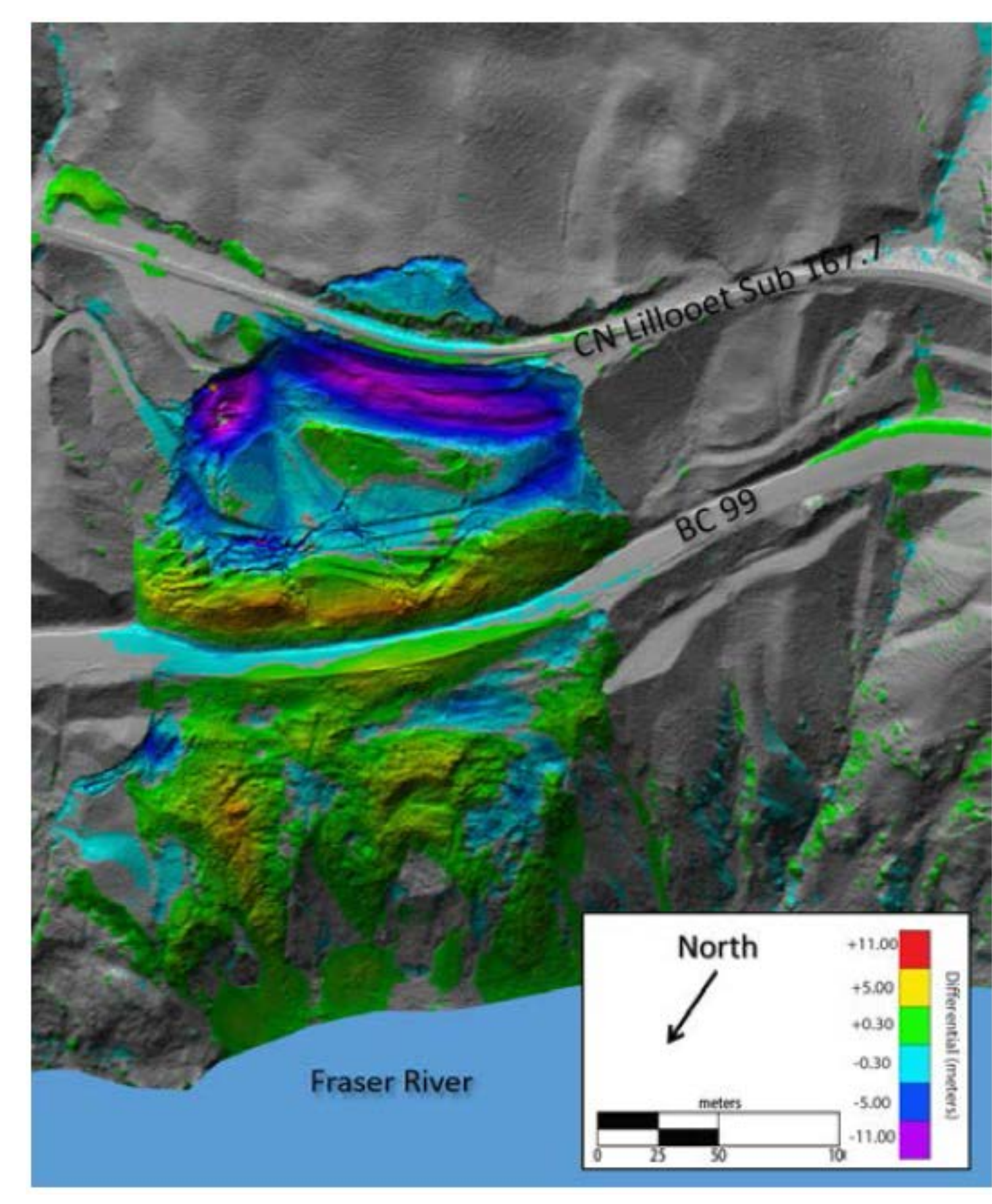

Lato et al. 2017

Mitchell et al. 2017. Regional scale landslide and erosion monitoring utilizing airborne LiDAR change detection analysis. 


\section{Application to Regional Scale Data}

- Reservoir area with numerous stakeholders potentially affected by landslides or erosion

- Baseline dataset collected in 2006 - Approximately $1 \mathrm{pt} / \mathrm{m}^{2}$ bare earth point density

- Second dataset collected in 2015 - Approximately $5 \mathrm{pt} / \mathrm{m}^{2}$ bare earth point density

- Total collection area is approximately $750 \mathrm{~km}^{2}$ - Large area required an efficient processing technique

- Area was subdivided and alignment process was automated using Polyworks 


\section{Detection of Landslide Areas}

2015 ALS Data

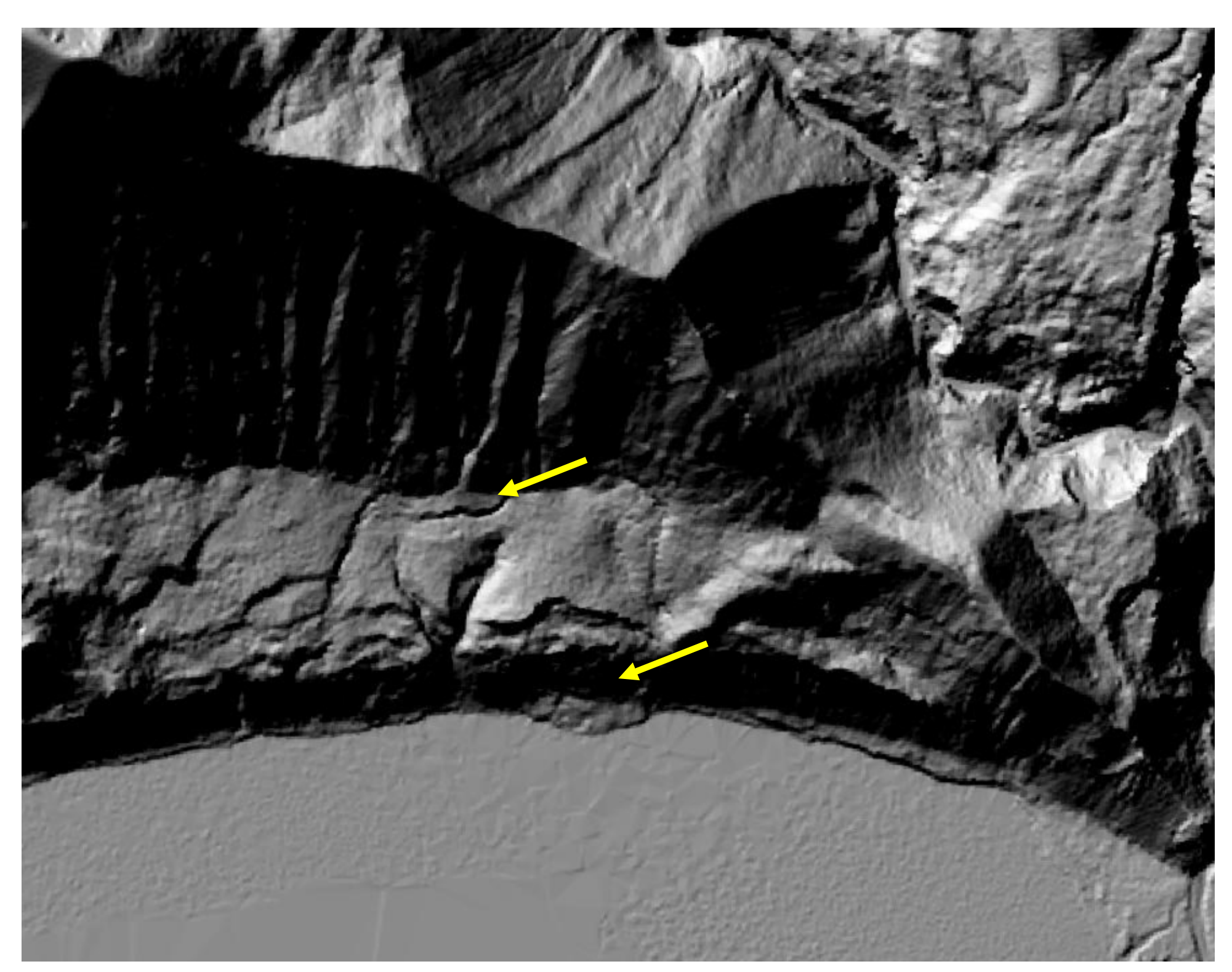

2015 vs 2006 Change Detection

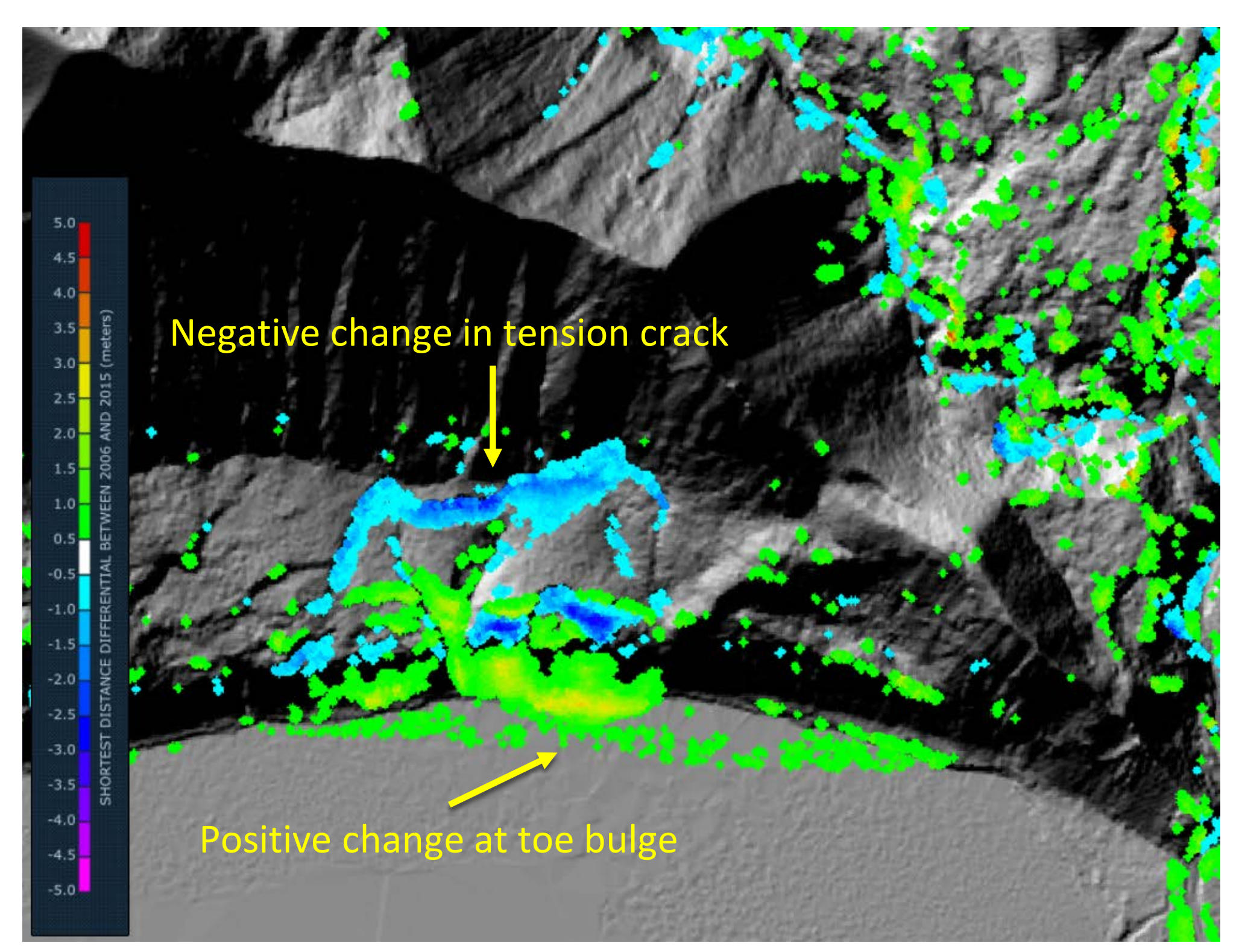

Mitchell et al. 2017. Regional scale landslide and erosion monitoring utilizing airborne LiDAR change detection analysis. 


\section{Field Verification}


Field verification of areas of change

1. Headscarp

2. Central zone, translational

movement

3. Toe bulge

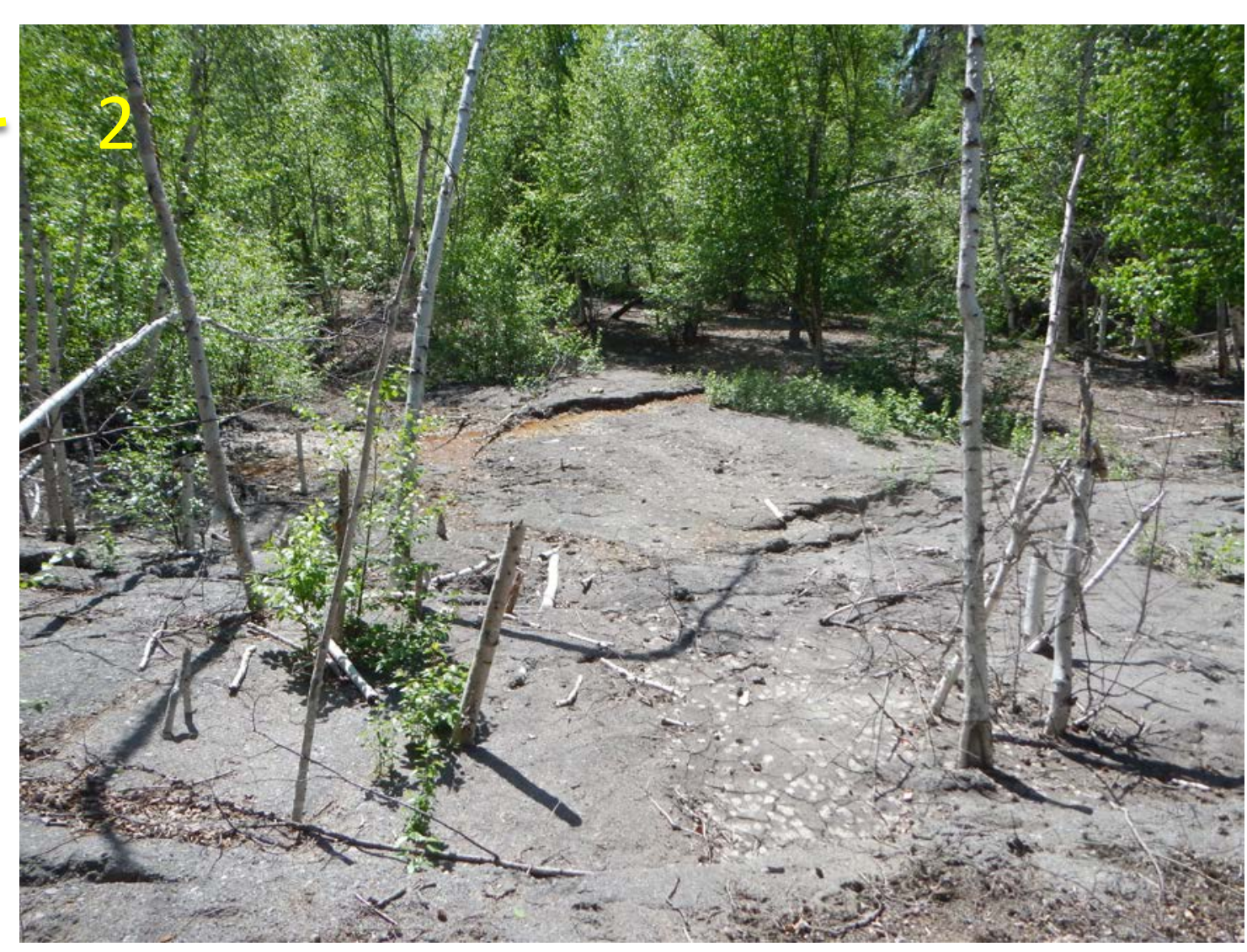




\section{Detection of Erosion Areas}

\section{ALS Data}

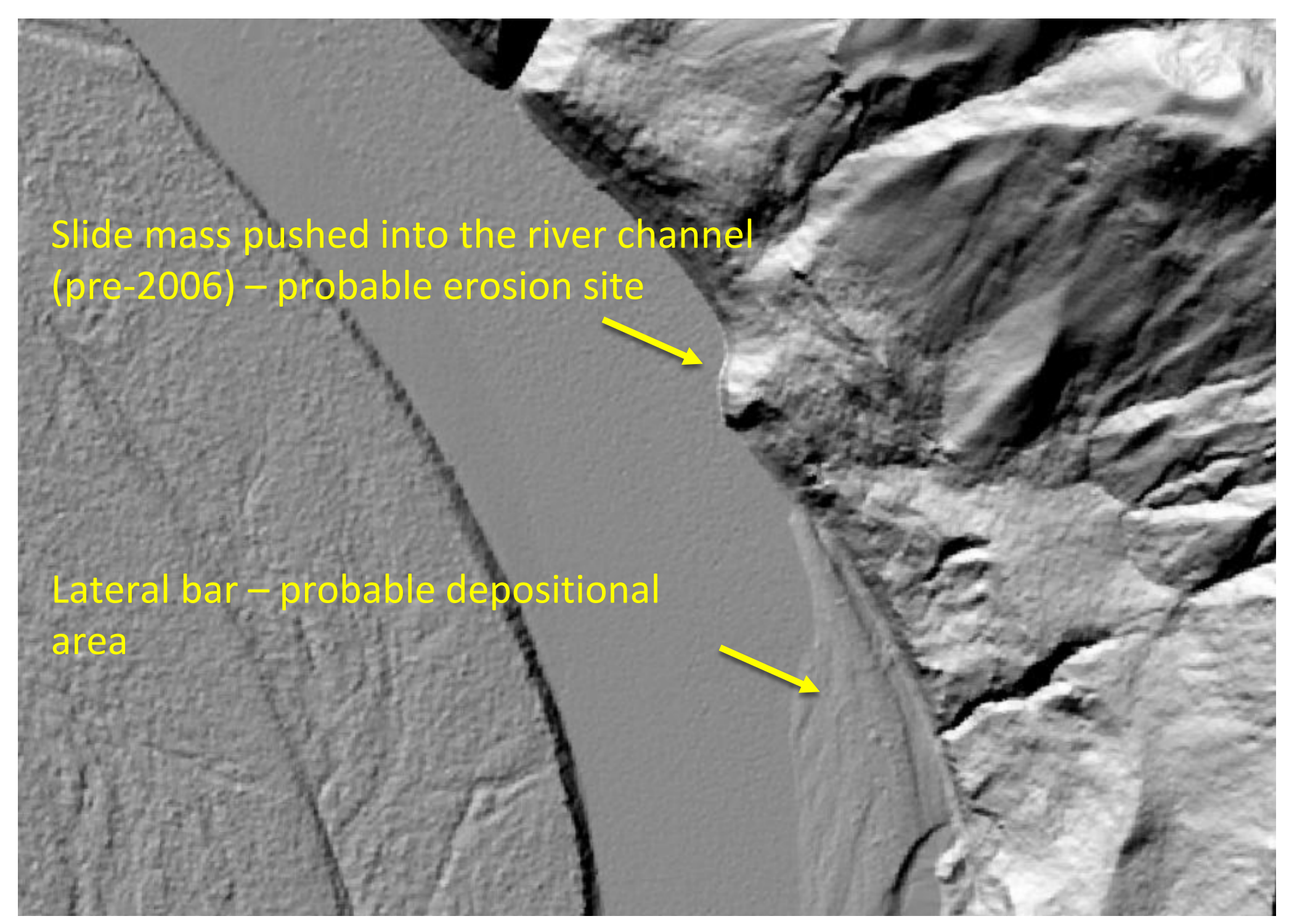

2006 vs 2015 Change Detection

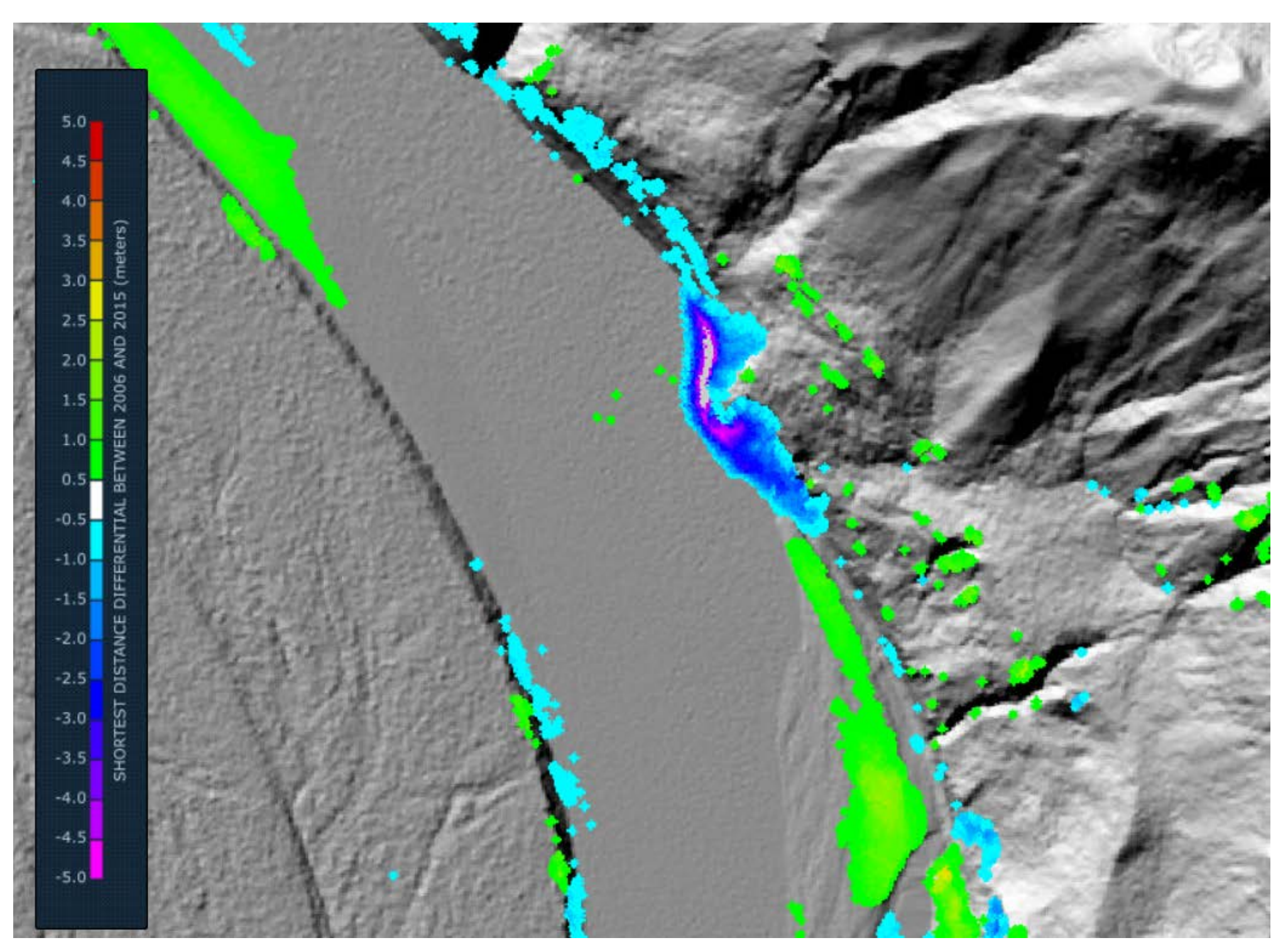




\section{Field Verification}

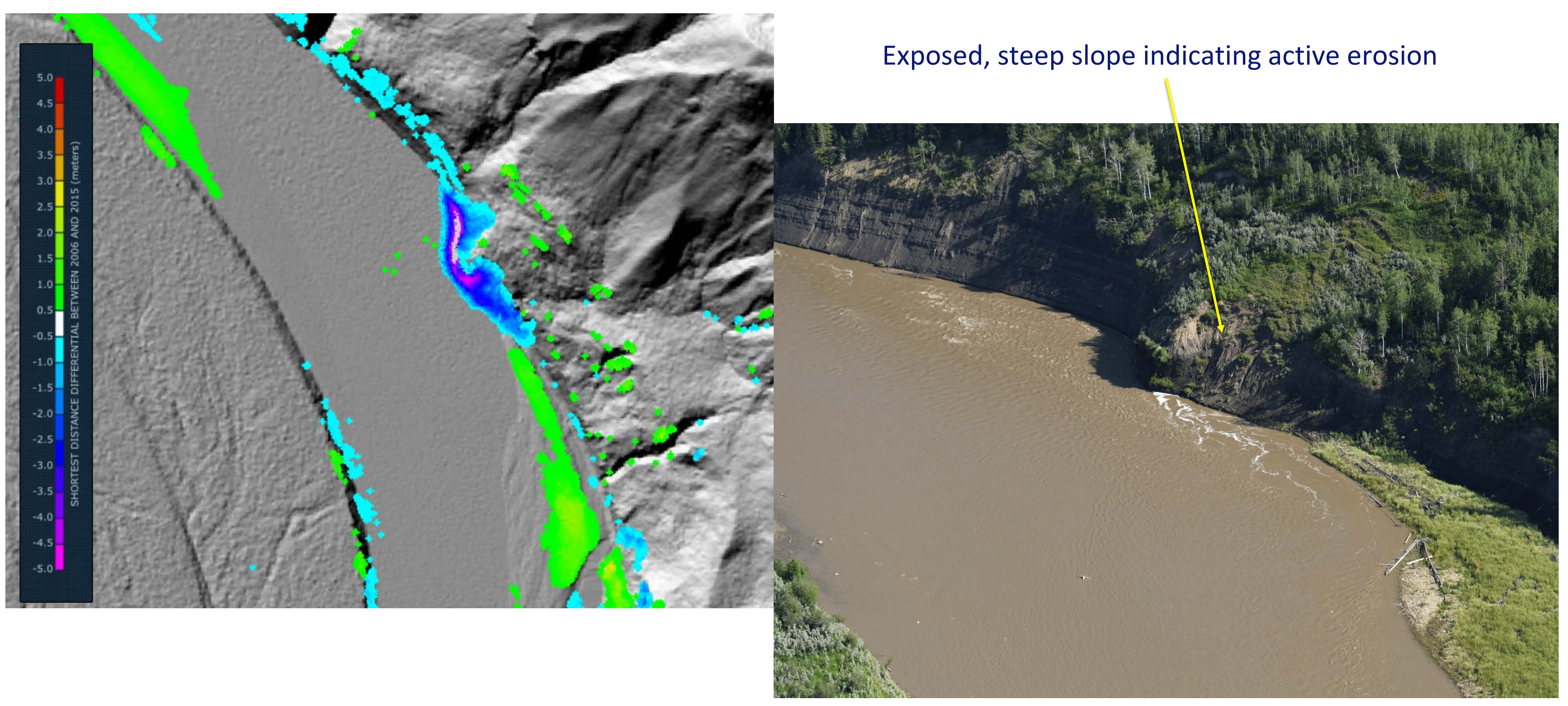

Mitchell et al. 2017. Regional scale landslide and erosion monitoring utilizing airborne LiDAR change detection analysis. 


\section{Spurious Change Detection Results}

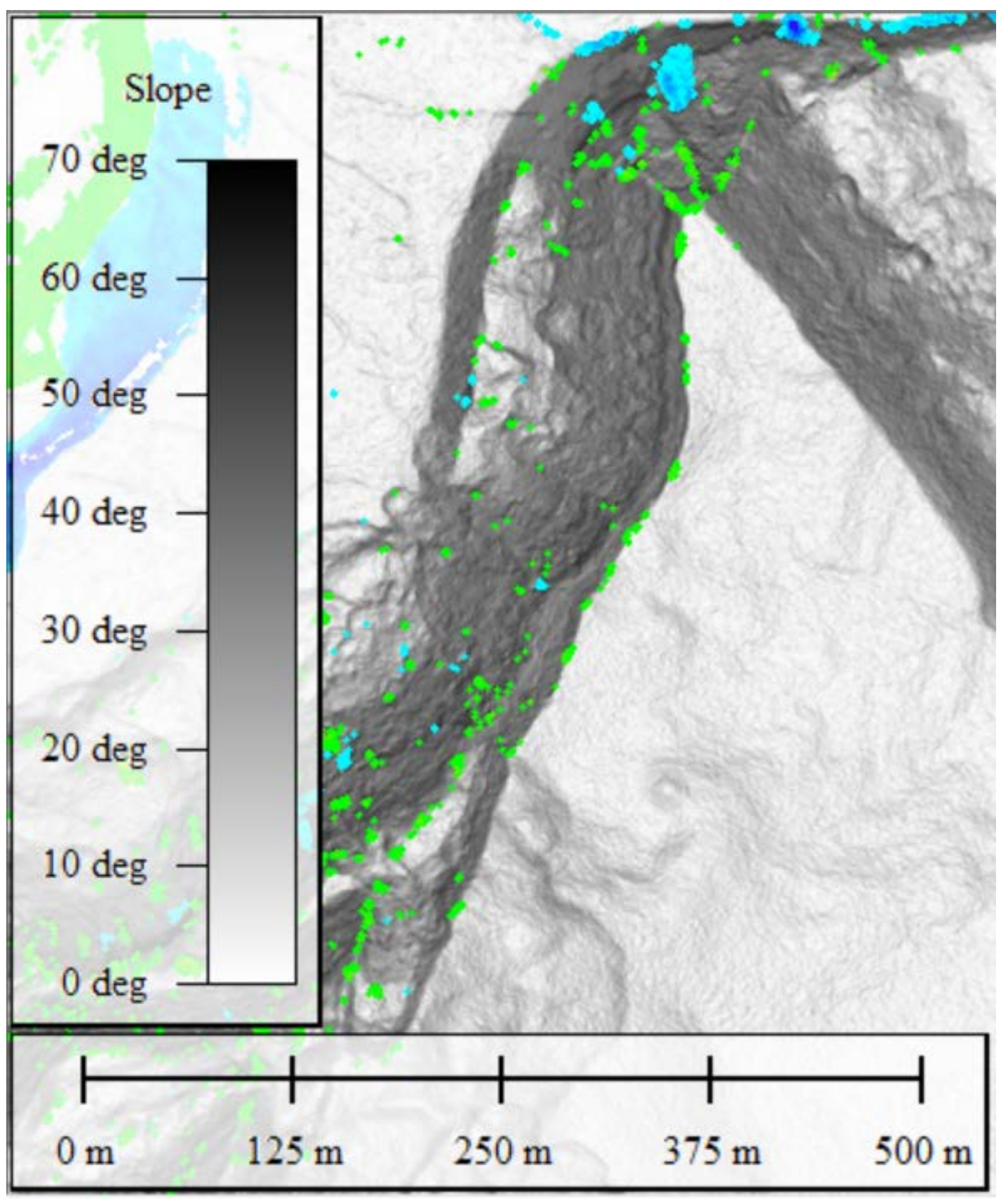

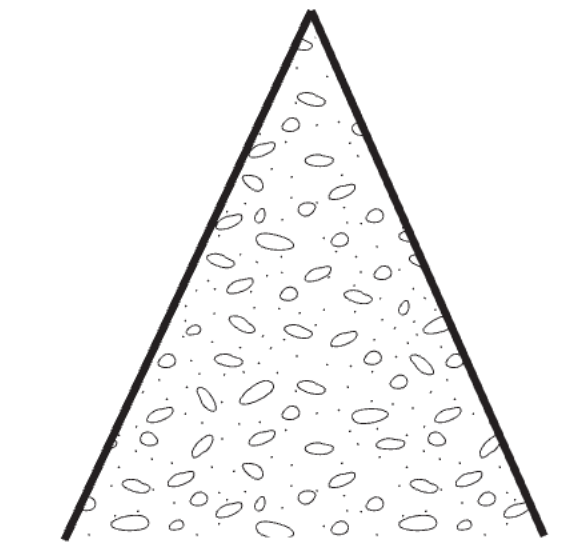

— Actual ground surface

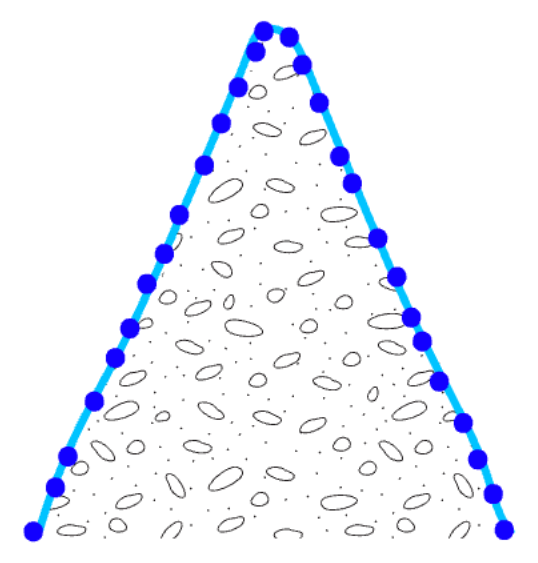

- Higher resolution ALS point cloud Higher resolution ALS interpolated ground model

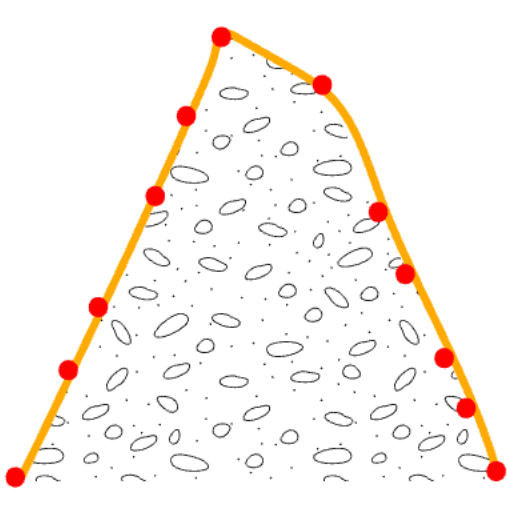

- Lower resolution ALS point cloud - Lower resolution ALS interpolated ground mode

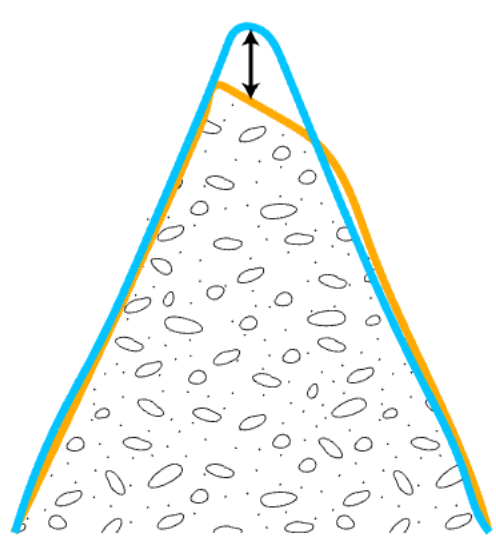

- Lower resolution ALS interpolated ground model - Higher resolution ALS interpolated ground mode $\rightarrow$ Measured difference between models

Apparent positive change can be detected when datasets with different Resolutions are used at features like ridge lines or gullies 


\section{Refined Analysis}

\section{Initial results}

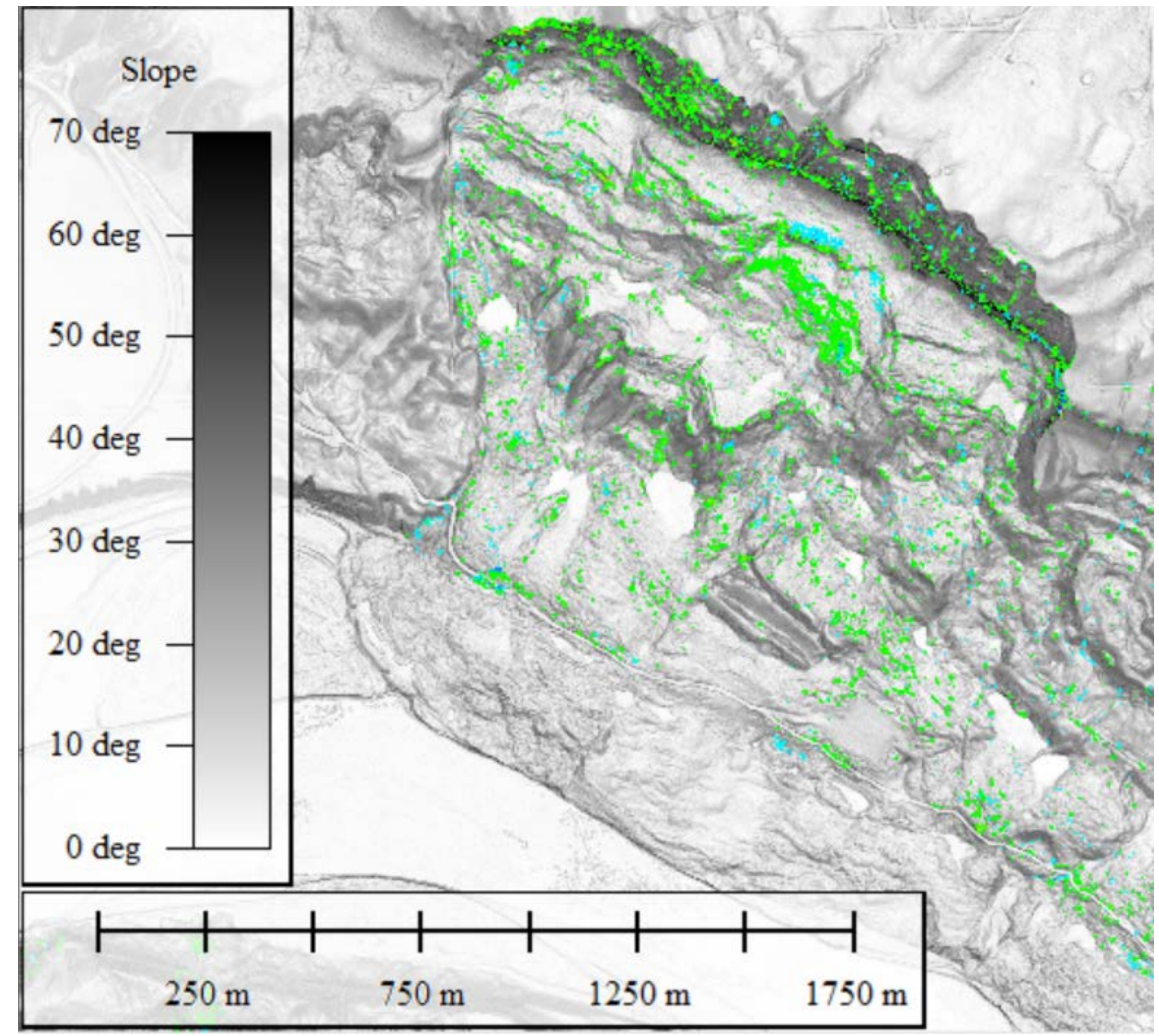

\section{Refined analysis}

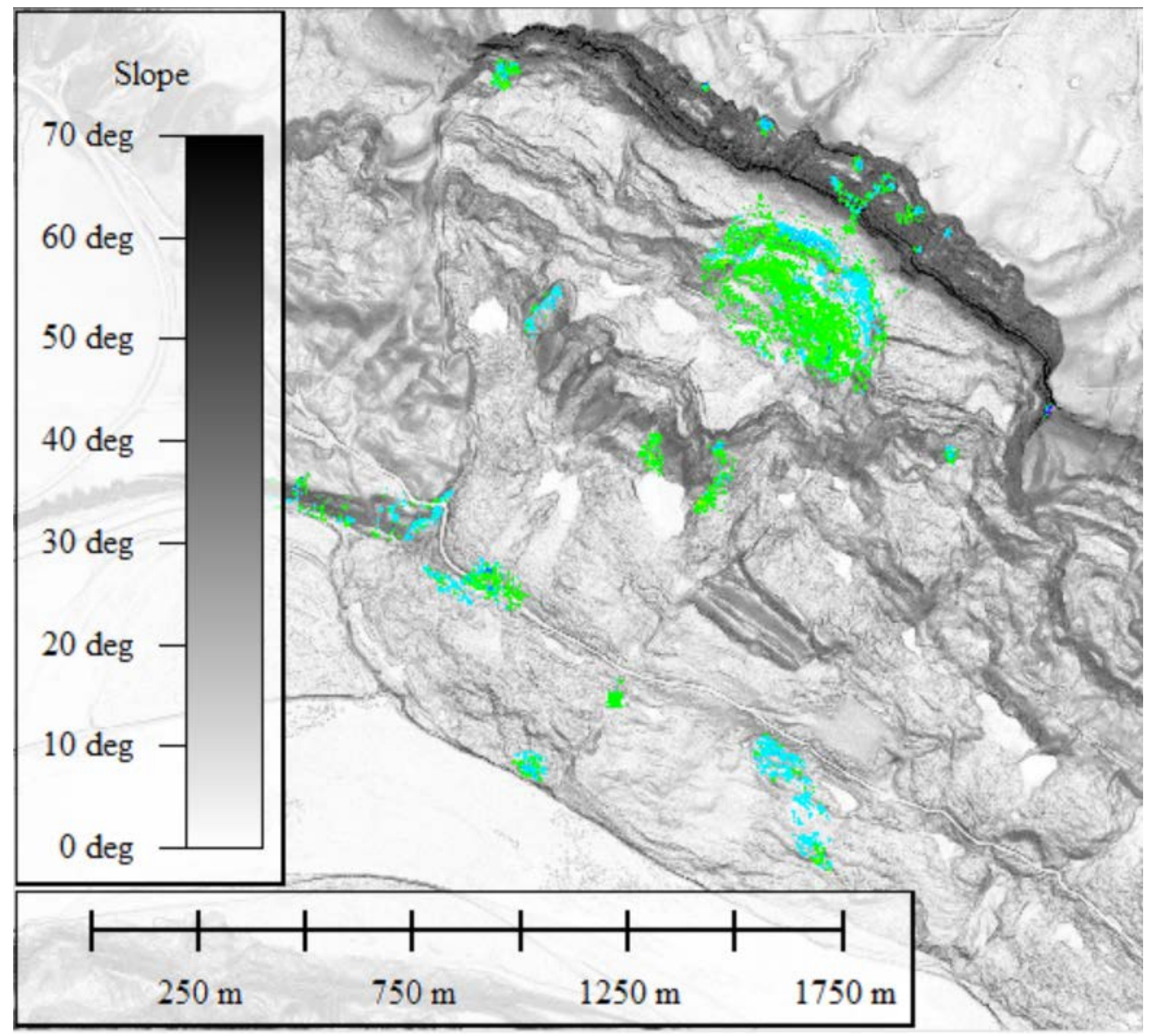

Select areas were re-aligned focusing on smaller areas to reduce the effects of spurious change, and better define areas of movement. 


\section{Web-based GIS data delivery}

- This amount of spatial data needs an effective way to be communicated

- Static maps can be used, but either a lot of maps need to be generated, or the results need to be down sampled

- GIS software is effective, but not all end users have access to this

- Web-based GIS platform developed for this project

- Project topographical and change detection results are stored on a secure server

- Allows users without GIS software to view and interact with the data - a web browser, username and password are the only requirements

- Other sources of data (other infrastructure, predicted project impacts, etc.) are also on the server and can be overlain on the data

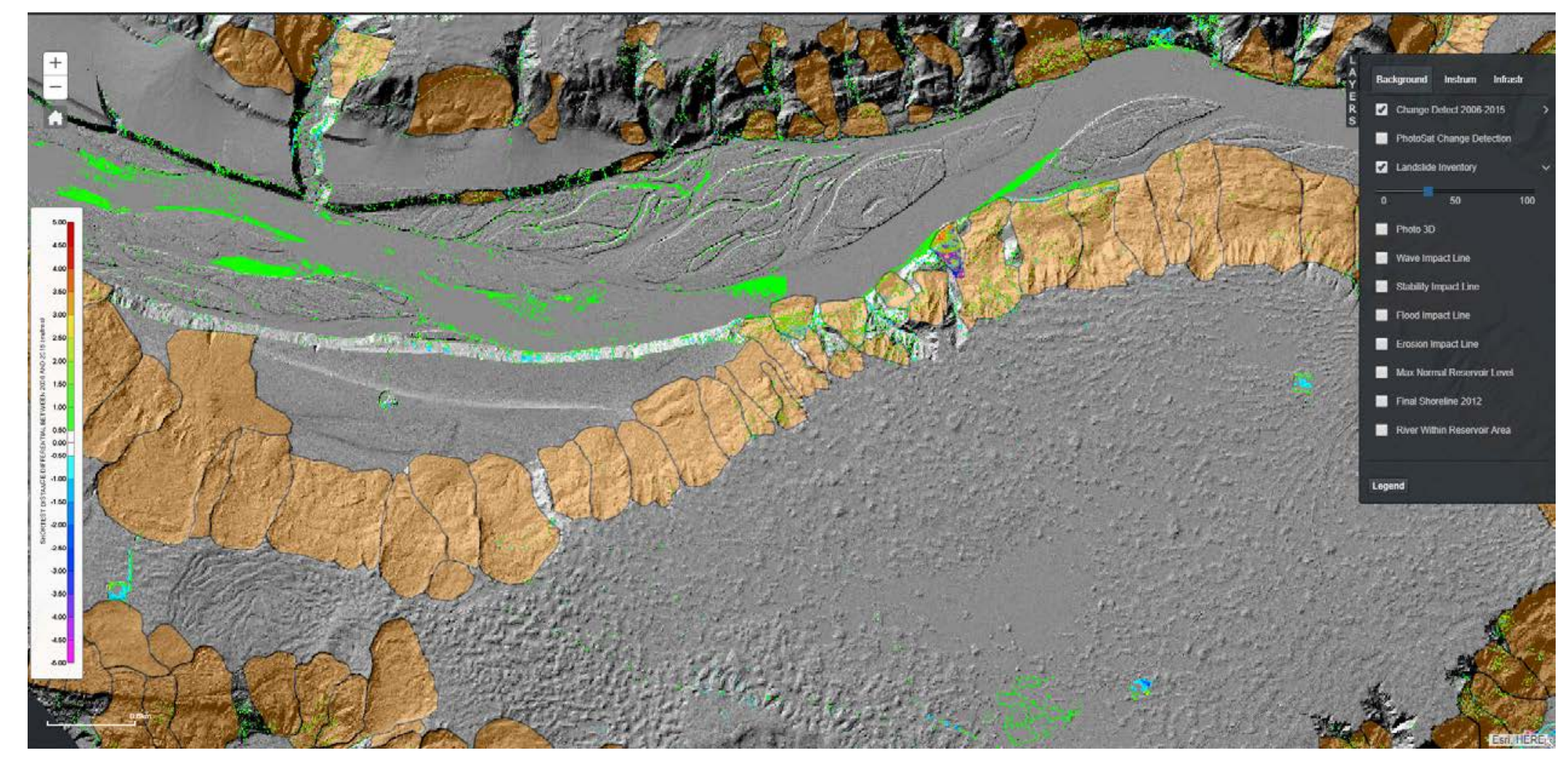


B|A|C| 